\title{
Panel Reactive Antibody Test
}

National Cancer Institute

\section{Source}

National Cancer Institute. Panel Reactive Antibody Test. NCI Thesaurus. Code C116210.

An assessment of the reactivity between host immune cells and donor human leukocyte antigen. This test is most commonly carried out in subjects awaiting transplant. The recipient's blood or serum is mixed with either a panel of lymphocytes from random blood donations or a potential donor's purified human leukocyte antigens (HLA). Host reactivity is scored as a percent. 